\title{
Usefulness of a screw tip stent retriever as a dilator during side-by-side placement of multiple stents for malignant hilar biliary obstruction
}

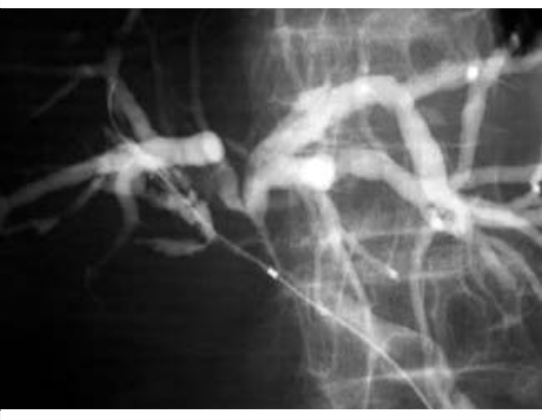

- Fig. 1 The left, right anterior, and right posterior bile ducts were obstructed by an unresectable gallbladder duct cancer.



- Fig. 2 During multiple stenting, none of the devices used were able to easily pass over the stricture, despite adjusting the scope position, because of interference with the jagged surface of the fully covered self-expandable metal stents and bending of the inferior bile duct due to the Billroth-I gastrectomy.

In malignant hilar biliary obstruction, an additional stent placement is often difficult after the placement of fully covered self-expandable metal stents (FCSEMSs) in a side-by-side fashion.

An 86-year-old man who had a history of Billroth-I gastrectomy presented with a malignant hilar biliary obstruction from unresectable gallbladder duct cancer. The left, right anterior, and right posterior bile ducts were obstructed (> Fig. 1). Initially, we attempted to place a $6-\mathrm{mm}$ FCSEMS (HANAROSTENT Biliary FullCover NEO, M.I. Tech Co., Ltd., Seoul, Korea) at the right anterior branch. Subsequently,

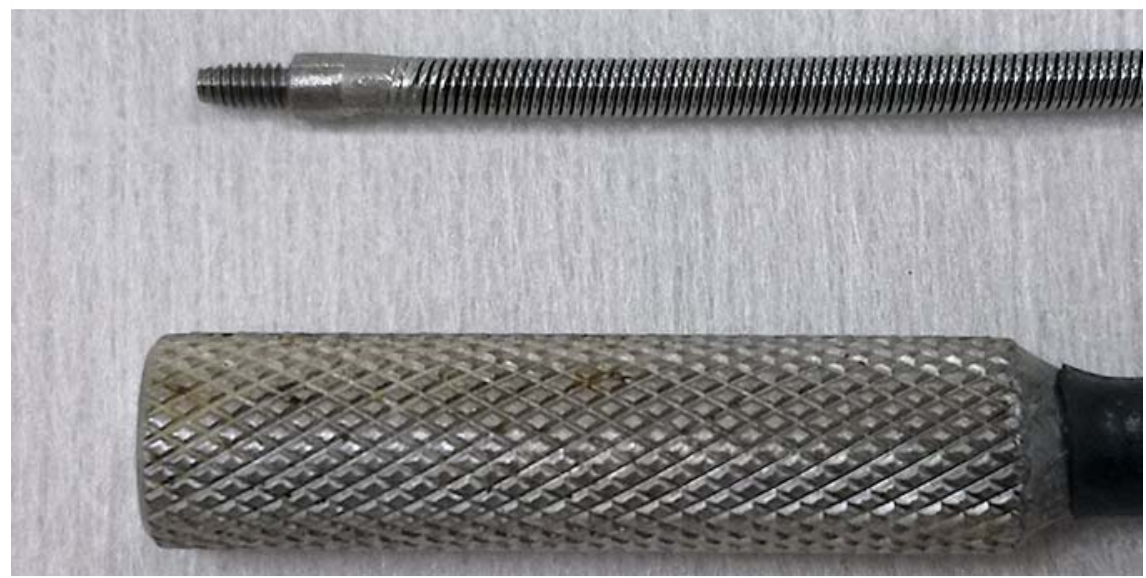

Fig. 3 The Soehendra stent retriever (SSR) has a screw tip, coil sheath, and a handle. The SSR was originally designed for removing plastic stents over a guidewire. The other application of the SSR is as a dilator of a tight biliary stricture.

we attempted to deploy a 6-mm FCSEMS to the left bile duct to facilitate the deployment of a plastic stent at the rightposterior branch in a side-by-side fashion. However, during multiple stenting, none of the devices used, namely the tapered cannulation catheter, balloon dilator, and sheath dilator, were able to easily pass over the stricture, despite adjusting the scope position, because of interference with the jagged surface of the FCSEMSs and bending of the inferior bile duct due to Billroth-I gastrectomy ( Fig. 2).

Clockwise rotation of the Soehendra stent retriever (SSR; COOK Medical Inc., Winston-Salem, NC, USA) generated a propulsive force in addition to pushing the catheter from the back end. The spiral motion of the SSR tip allowed it to easily pass over the jagged SEMS surface and stricture [1-4] (ฉFig.3, > Fig.4, - Fig. 5, - Video 1). After the SSR dilated the stricture, the counterclockwise rotation allowed easy retraction without compromising the SEMSs. Finally, we succeeded in placing multiple stents in a side-by-side fashion. Thus, the use of the SSR as a dilator is one of the viable options when it becomes difficult to

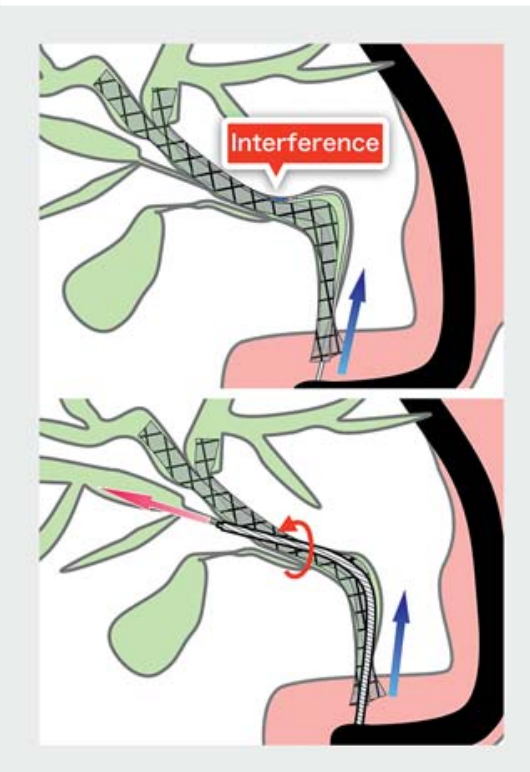

Fig. 4 Clockwise rotation of the Soehendra stent retriever (SSR) generated a propulsive force in addition to pushing the catheter from the back end. The spiral motion of the SSR tip allowed it to easily pass over the jagged self-expandable metal stent surface and the stricture.

pass over and dilate the malignant stricture owing to interference with SEMSs or anatomical problems. 


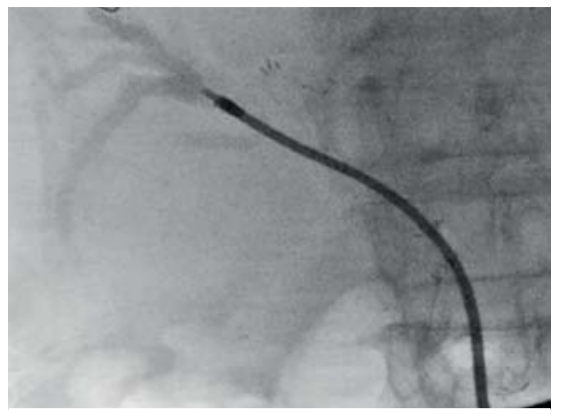

Fig. 5 Finally, we succeeded in placing multiple stents in a side-by-side fashion without compromising them.
Endoscopy_UCTN_Code_TTT_1AS_2AF

\section{Competing interests}

Akio Katanuma received honoraria as lecture fee from Olympus Co., Tokyo Japan. Any other authors have no conflicts of interest to declare.

\section{The authors}

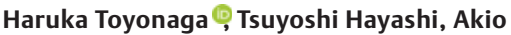 Katanuma}

Center for Gastroenterology, Teine Keijinkai Hospital, Hokkaido, Japan

\section{Corresponding author}

\section{Haruka Toyonaga, MD}

Center for Gastroenterology, Teine-keijinkai Hospital, 1-40-1-12 Maeda, Teine-ku,

Sapporo 006-8555, Japan

Fax: +81-11-685-2967

toyonaga.pc@gmail.com

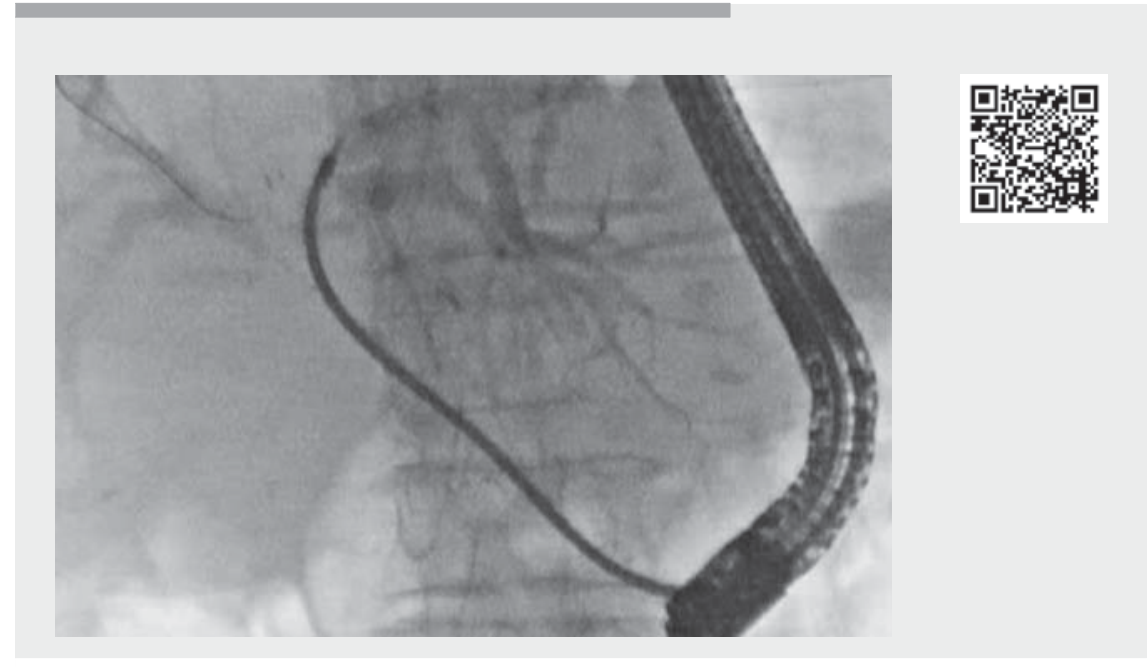

$\checkmark$ Video 1 This video demonstrates the use of the Soehendra stent retriever is one of the options when it is difficult to dilate the stricture during the placement of multiple SEMSs in a side-by-side fashion.

\section{References}

[1] Francisco V, Terrence JB, Richard AK et al. New application for the Soehendra stent retriever. Gastrointest Endosc 1998; 47: $109-110$

[2] Viazis N, Armonis A, Tsoris S et al. Treating a malignant biliary stricture using the Soehendra stent retriever: overcoming the boundaries. Ann Gastroenterol 2005; 18 : 346-348

[3] Kato H, Kawamoto H, Noma $\mathrm{Y}$ et al. Dilatation by Soehendra stent retriever is feasible and effective in multiple deployment of metallic stents to malignant hilar biliary strictures. Hepatogastroenterology 2013; 60: 286-290

[4] Mohamed E, Kröner PT, Kumar U et al. Use of a Soehendra stent retriever in dilation of an anastomotic biliary stricture in a post-liver transplant patient. Endoscopy 2016; 48 (Suppl. 01): E35-E36

\section{Bibliography}

Endoscopy 2022; 54: E698-E699

DOI 10.1055/a-1757-9208

ISSN 0013-726X

published online 28.2.2022

(c) 2022. Thieme. All rights reserved.

Georg Thieme Verlag KG, Rüdigerstraße 14,

70469 Stuttgart, Germany

\section{ENDOSCOPY E-VIDEOS}

https://eref.thieme.de/e-videos

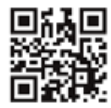

Endoscopy E-Videos is an open access online section, reporting on interesting cases and new techniques in gastroenterological endoscopy. All papers include a high quality video and all contributions are freely accessible online. Processing charges apply (currently EUR 375), discounts and wavers acc. to HINARI are available.

This section has its own submission website at

https://mc.manuscriptcentral.com/e-videos 